\title{
Fitotoxicidade e citogenotoxicidade da água e sedimento de córrego urbano em bioensaio com Lactuca sativa
}

\author{
Luiz C. de A. Rodrigues', Sandro Barbosa', Murilo Pazin', \\ Bianca de S. Maselli' ${ }^{1}$ Luiz A. Beijo ${ }^{2}$ \& Fábio Kummrow ${ }^{3}$
}

\begin{abstract}
RESUMO
Objetivou-se, com este trabalho, avaliar a influência espacial e temporal da fitotoxicidade e da citogenotoxicidade da água e do sedimento de córrego urbano quanto às características germinativas e de crescimento inicial de Lactuca sativa. Amostras de água e de sedimento foram coletadas em 5 pontos do Córrego do Pântano (Alfenas, Minas Gerais), no período de outubro de 2010 a julho de 2011 e as concentrações dos metais $\mathrm{Cd}, \mathrm{Pb}$ e $\mathrm{Zn}$ foram quantificadas. Os ensaios de fitotoxicidade e de citogenotoxicidade foram realizados com as amostras de água e extratos aquosos dos sedimentos. Os parâmetros avaliados foram taxa de germinação, comprimento de raízes, biomassa fresca e seca, índice mitótico e a frequência de anormalidades cromossômicas. Constataram-se maiores concentrações de $\mathrm{Cd}$ e $\mathrm{Pb}$ nas amostras de água coletadas nos meses com a ocorrência de precipitações pluviométricas. Água e sedimento apresentaram efeito fitotóxico sobre germinação, biomassa fresca e seca de Lactuca sativa. O comprimento de raízes foi estimulado e apenas as amostras de água reduziram o índice mitótico. Evidenciou-se, também, variação temporal significativa relacionada com o regime pluviométrico apenas para o teste de fitotoxicidade.
\end{abstract}

Palavras-chave: alface, toxicidade, sazonalidade

\section{Phytotoxicity and cytogenotoxicity of water and sediment of urban stream in bioassay with Lactuca sativa}

\begin{abstract}
The aim of this study was to evaluate the spatial and temporal influence of the phytotoxicity and cytogenotoxicity of water and sediment of urban stream on the germination and initial growth of Lactuca sativa. Samples were collected from water and sediment at five sites of the Pântano Stream (Alfenas, Minas Gerais) during the period from October 2010 to July 2011. The concentrations of the metals $\mathrm{Cd}, \mathrm{Pb}$ and Zn were quantified. Moreover, phytotoxicity and cytogenotoxicity were tested with samples of water and aqueous extracts of sediments. The evaluated end points were the germination rate, root length, fresh and dry weight, mitotic index and frequency of chromosomal abnormalities. Higher levels of $\mathrm{Cd}$ and $\mathrm{Pb}$ were verified in water samples collected during the rainy months. Water and sediment showed phytotoxic effect on germination, fresh weight and dry weight of Lactuca sativa. Root length was stimulated and only samples of water reduced the mitotic index. Significant temporal variation related to rainfall was observed only for phytotoxicity tests.
\end{abstract}

Key words: lettuce, toxicity, seasonality

\footnotetext{
${ }^{1}$ Instituto de Ciências da Natureza/UNIFAL-MG, Campus Alfenas. Rua Gabriel Monteiro da Silva, 700, Centro, CEP 37130-000, Alfenas, MG. Fone: (35) 3299-1419. E-mail: rodrigues.Ica@gmail.com; sandrobiogen@gmail.com; murilopazin@hotmail.com; bsmaselli@gmail.com ${ }^{2}$ Instituto de Ciências Exatas/UNIFAL-MG, Campus Alfenas. Fone: (35) 3299-1483. E-mail: luizbeijo@yahoo.com.br ${ }^{3}$ UNIFESP, Campus Diadema. Rua Prof. Artur Ridel, 275, CEP 09972-270, Diadema, SP. Fone: (11) 3319-3574. E-mail: fkummrow@unifesp.br
} 


\section{INTRODUÇÃO}

Fontes pontuais e difusas de poluição podem alterar significativamente as características da água de um corpo hídrico, inviabilizando sua utilização. Efluentes domésticos e industriais, tratados ou não, são frequentemente dispostos nos corpos d'água adjacentes a áreas urbanizadas e os poluentes neles contidos causam alterações físicas, químicas ou biológicas na qualidade da água.

O Córrego do Pântano está localizado na região noroeste da cidade de Alfenas, MG, e recebe despejos de efluentes domésticos de bairros residenciais e do distrito industrial, que abriga empresas dos setores têxtil e siderúrgico. Alvim et al. (2011) caracterizaram os efeitos citogenotóxicos de efluentes têxteis que são lançados no Córrego do Pântano, antes e após o processo de tratamento. Contudo, os prováveis impactos ambientais causados pelo despejo de efluentes domésticos e industriais neste córrego não foram estudados.

Efluentes industriais podem conter elevadas cargas de matéria orgânica, nutrientes e vários outros poluentes como metais, agrotóxicos e uma ampla gama de poluentes orgânicos. Além disso, parte da poluição gerada em áreas urbanas tem origem no escoamento superficial das águas pluviais sobre áreas impermeáveis que podem carrear materiais orgânicos e inorgânicos, dissolvidos ou em suspensão, aos mananciais via redes de drenagem (Bollmann \& Marques, 2006).

Os efluentes de indústrias têxteis interferem, em particular, na qualidade ambiental dos ecossistemas aquáticos e da água para consumo humano (Alvim et al., 2011). Esses efluentes estão associados à presença de metais e a outras substâncias nocivas provenientes dos produtos químicos empregados nos seus processos e que podem ser encontrados nos corpos d'água que os recebem. Tem crescido o número de estudos ecotoxicológicos sobre corantes têxteis devido à sua toxicidade, além da toxicidade dos seus produtos de degradação biótica e abiótica (Gomes et al., 2012).

Quando aderidos aos sólidos em suspensão, os contaminantes presentes na coluna d'água tendem a ser transportados por longas distâncias ou sedimentar durante o percurso, contaminando outros trechos do corpo hídrico (Czerniawska-Kusza \& Kusza, 2011). Por este motivo é crescente a preocupação com o potencial poluidor dos sedimentos de corpos d'água que recebem efluentes domésticos ou industriais.

Os testes de toxicidade empregados para avaliar a qualidade ambiental representam uma alternativa para complementar as análises químicas (Wilke et al., 2008). Testes em que se utilizam plantas superiores são considerados eficientes para a avaliação e monitoramento da toxicidade de poluentes e têm sido utilizados em estudos sobre a fitotoxicidade de águas e sedimentos contaminados (Fernandes et al., 2007; Czerniawska-Kusza \& Kusza, 2011). Sua principal vantagem é a ampla variedade de parâmetros de toxicidade, como a taxa de germinação, ganho de biomassa, alongamento de raízes e aspectos bioquímicos, além de apresentar baixo custo e possibilidade de serem realizados continuamente (Žaltauskaite \& Čypaitè, 2008).

A Lactuca sativa L. (alface) está entre os organismos-teste mais utilizados para avaliar a fitotoxicidade e a citogenotoxicidade de efluentes domésticos e industriais (Žaltauskaite \& Čypaitè,
2008; Andrade et al., 2010) sendo esta espécie recomendada por agências internacionais para tal finalidade.

Neste trabalho objetivou-se avaliar a influência espacial e temporal da fitotoxicidade e da citogenotoxicidade da água e sedimento do Córrego do Pântano sobre os aspectos germinativos e o crescimento inicial de Lactuca sativa $\mathrm{L}$.

\section{Material e Métodos}

O Córrego do Pântano ( $21^{\circ} 24^{\prime}$ 54,3” S, 45 57' 39,3”' O) está localizado no município de Alfenas, $\mathrm{MG}$, sua extensão é de aproximadamente $3 \mathrm{~km}$ com cerca de $2 \mathrm{~m}$ de largura. Suas águas recebem esgotamentos sem tratamentos de dois bairros residenciais e efluentes do distrito industrial enquanto sua foz se localiza em um braço do Lago de Furnas cuja água é utilizada para abastecimento público, dessedentação de animais e irrigação de hortaliças e aquicultura.

Amostras de água foram coletadas em cinco pontos do Córrego do Pântano (Figura 1) acerca de $20 \mathrm{~cm}$ de profundidade, em que o ponto $1(\mathrm{P} 1)$ se refere à nascente e é constituído de uma mina de água utilizada para abastecimento público $\left(21^{\circ} 24^{\prime}\right.$ $53,3^{\prime \prime} \mathrm{S}, 45^{\circ} 57^{\prime} 39,8^{\prime \prime} \mathrm{O}$ ); ponto 2 (P2) é o principal ponto de lançamento de esgoto proveniente de dois bairros residenciais $\left(21^{\circ} 24^{\prime} 49,5^{\prime \prime} \mathrm{S}, 45^{\circ} 57^{\prime} 43,8^{\prime \prime} \mathrm{O}\right)$; ponto 3 (P3) é o ponto a partir do qual não ocorrem mais despejos de efluentes domésticos $\left(21^{\circ}\right.$ $24^{\prime} 35,7^{\prime}$ ' S, $45^{\circ} 57^{\prime} 53,7^{\prime}$ ' O); ponto 4 (P4) encontra-se na área de despejo do efluente tratado de duas indústrias têxteis e está à jusante da área que recebe o lixiviado oriundo de um depósito de moldes de areia de fundição $\left(21^{\circ} 24^{\prime} 08,7^{\prime \prime} \mathrm{S}, 45^{\circ} 58^{\prime} 15,6^{\prime \prime} \mathrm{O}\right)$ e o ponto 5 (P5) localizado à jusante do despejo do efluente bruto de um abatedouro e da confluência com o Córrego do Pântano $\mathrm{I}$, que passa pelo aterro comum do município $\left(21^{\circ} 24^{\prime} 0,8^{\prime \prime} \mathrm{S}\right.$, $45^{\circ} 58^{\prime} 29,0^{\prime \prime} \mathrm{O}$ ). A coleta de amostras de sedimento foi possível apenas nos pontos $\mathrm{P} 2, \mathrm{P} 3 \mathrm{e} \mathrm{P} 4$.

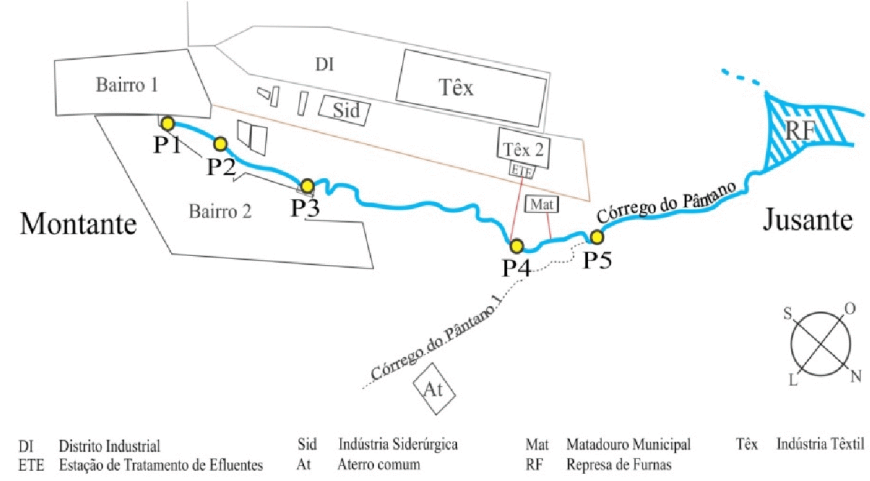

Figura 1. Mapa com os pontos de coleta e principais características do Córrego do Pântano

As coletas foram realizadas mensalmente, no período de outubro de 2010 a julho de 2011, visando detectar possíveis efeitos tóxicos em diferentes regimes pluviométricos. As amostras de água e de sedimento foram coletadas de acordo com a metodologia proposta por Jardim et al. (2008) e Mitteregger Júnior et al. (2006) respectivamente. Os dados de precipitação pluviométrica foram obtidos junto à Agência Nacional de Águas (ANA).

Em laboratório, as amostras de sedimentos foram desidratadas a $45 \pm 2{ }^{\circ} \mathrm{C}$ até atingir peso constante. Posteriormente, as 
amostras secas foram trituradas, padronizadas em malha fina $\left(1 \mathrm{~mm}^{2}\right)$ e armazenadas em sacos plásticos protegidos da luz e da umidade. A partir dessas amostras foram produzidos extratos aquosos dos sedimentos. Alíquotas das amostras trituradas de sedimento foram diluídas em água destilada na proporção de $1: 4 \mathrm{~m} / \mathrm{v}$ e a solução foi agitada em câmara incubadora com agitação orbital $\left(\right.$ Marconi $^{\circledR}$ ) por $24 \mathrm{~h}$; as soluções resultantes foram centrifugadas a $4500 \mathrm{rpm}$ durante 30 min e os sobrenadantes foram, então, separados e submetidos aos testes de fitotoxicidade.

Alíquotas das amostras de água foram submetidas à análise química para determinação das concentrações de $\mathrm{Cd}, \mathrm{Pb}$ e $\mathrm{Zn}$. A digestão de $50 \mathrm{~mL}$ das amostras líquidas previamente filtrados, foi realizada com $5 \mathrm{~mL}$ de $\mathrm{HNO}_{3}$ concentrado (P.A.) e $5 \mathrm{~mL}$ de $\mathrm{H}_{2} \mathrm{O}_{2}$ (35\% - P.A.). As soluções obtidas foram aquecidas a $90 \pm$ $5{ }^{\circ} \mathrm{C}$ até sua redução para $10 \mathrm{~mL}$. As amostras digeridas foram transferidas quantitativamente para balão volumétrico de 25 $\mathrm{mL}$ e o volume aferido com água ultrapura. As quantificações $\mathrm{de} \mathrm{Cd}$ e $\mathrm{Pb}$ foram realizadas por espectrofotometria de absorção atômica com forno de grafite (EAA-FG, Shimadzu ${ }^{\circledR}$ AA-7000) e a do $\mathrm{Zn}$ por espectrofotometria de absorção atômica por chama (EAA-chama, Shimadzu ${ }^{\circledR}$ AA-7000). Para obtenção das curvas analíticas foram utilizadas soluções padrão de $1000 \mathrm{mg} \mathrm{L}^{-1}$ $\left(\right.$ Specsol $\left.^{\circledR}\right)$.

Frações das amostras de sedimentos trituradas permitiram a determinação das concentrações de $\mathrm{Cd}, \mathrm{Pb}, \mathrm{Zn}$ e Ni. Alíquotas de aproximadamente $4 \mathrm{~g}$ dos sedimentos foram digeridas com $20 \mathrm{~mL}$ de água régia $\left(\mathrm{HCl} / \mathrm{HNO}_{3} 3: 1 \mathrm{v} / \mathrm{v}\right)$ a $90 \pm 5{ }^{\circ} \mathrm{C}$ por $2 \mathrm{~h}$. Após a liberação de fumos a mistura foi filtrada e transferida quantitativamente para balão volumétrico de $25 \mathrm{~mL}$, tendo o volume aferido com água ultrapura. $\mathrm{Na}$ quantificação dos metais empregou-se espectrofotometria de absorção atômica por chama (EAA-chama, Shimadzu AA-7000).

$O$ teor de matéria orgânica nos sedimentos foi determinado pelo método de calcinação a $500{ }^{\circ} \mathrm{C}$. Para isto, $4 \mathrm{~g}$ de cada amostra previamente secada a $105^{\circ} \mathrm{C}$, foram levados ao forno tipo mufla e aquecidos a $500{ }^{\circ} \mathrm{C}$ por $5 \mathrm{~h}$. Em seguida, foram determinadas as diferenças entre o peso inicial e final indicando o teor de matéria orgânica total presente.

Em todos os ensaios foi utilizado o organismo-teste $L$. sativa cv. Grand Rapids (alface) cujos parâmetros avaliados foram: taxa de germinação (TG); comprimento de raízes (CR); biomassa fresca das plântulas (MF) e biomassa seca total (MT). Os testes para avaliação da fitotoxicidade foram realizados de acordo com Ribeiro et al. (2012) com adaptações utilizando-se $3 \mathrm{~mL}$ das amostras de água e dos extratos aquosos das amostras dos sedimentos. Água destilada foi empregada como controle negativo. As sementes de L. sativa foram expostas às amostras e mantidas em câmara de germinação tipo BOD $\left(\right.$ Cienlab $\left.^{\circledR}\right)$ em temperatura controlada de $20 \pm 2{ }^{\circ} \mathrm{C}$ e fotoperíodo de $12 \mathrm{~h}$, pelo período de $72 \mathrm{~h}$.

A TG foi avaliada após 24 h. Em seguida, em 72 h foram feitas as medidas do CR e da MF de 10 plântulas por parcela, coletadas aleatoriamente. Posteriormente, essas 10 plântulas foram agrupadas e secadas durante $24 \mathrm{~h}$ em estufa $45 \pm 2{ }^{\circ} \mathrm{C}$ para obtenção dos dados de MS.

Nas mesmas condições dos testes anteriores foi realizada a germinação ressaltando-se que, do total de 4.200 sementes,
1.920 sementes de L. sativa foram expostas às amostras de água e aos extratos dos sedimentos, respectivamente, para obtenção de meristemas apicais das raízes a serem utilizados no teste de citogenotoxicidade. Como controle negativo foi utilizada água destilada e, como controle positivo, uma solução $20 \mathrm{mg}$ $\mathrm{L}^{-1}$ de sulfato de alumínio $\left(\mathrm{Al}_{2} \mathrm{O}_{12} \mathrm{~S}_{3}\right)$. Após $24 \mathrm{~h}$ de exposição as raízes foram coletadas, fixadas em Carnoy e armazenadas a $-18 \pm 1{ }^{\circ} \mathrm{C}$. As lâminas foram confeccionadas pelo método de esmagamento descrito por Alvim et al. (2011).

O IM foi determinado utilizando-se a Eq. 1, em que NCM é o número de células em mitose e NTC o número total de células.

$$
\mathrm{IM}=\frac{\mathrm{NCM}}{\mathrm{NTC}} \times 100
$$

As AC avaliadas foram micronúcleos, c-metáfases, pontes cromossômicas, cromossomos perdidos e cromossomos aderentes (Stickiness) cujas frequências foram determinadas pela Eq. 2 sendo NTAC o número total de anormalidades cromossômicas e NTC o número total de células.

$$
\mathrm{AC}=\frac{\mathrm{NTAC}}{\mathrm{NTC}} \times 100
$$

Os dados das dez coletas realizadas foram agrupados em bimestres visando minimizar o efeito de interferências ambientais nas amostras coletadas mensalmente. Nos testes de fitotoxicidade para as amostras de água, o delineamento experimental adotado foi o inteiramente casualizado (DIC) em esquema fatorial $6 \times 5$, sendo considerados fatores o Tratamento (água de 5 pontos de coleta +1 controle negativo) e o Tempo (5 épocas de coletas). Três repetições (placas) com 60 sementes de L. sativa foram utilizadas para cada coleta totalizando 10.800 sementes (6 tratamentos $\mathrm{x} 10$ coletas $\mathrm{x} 3$ repetições x 60 sementes). Para os extratos dos sedimentos o delineamento experimental adotado foi em blocos casualizados (DBC), em esquema fatorial 3 x 5 mais um tratamento adicional, considerados fatores o Tratamento (extratos dos sedimentos dos 3 pontos de coleta) e o Tempo (5 épocas de coleta).

O controle negativo foi analisado como tratamento adicional para as amostras de sedimento tendo em vista que este não foi realizado mensalmente e, portanto, não pode interagir com o fator Tempo. Foram utilizadas três repetições com 60 sementes de L. sativa cada uma totalizando 5.580 sementes ( 3 pontos de coleta x 10 coletas x 3 repetições x 60 sementes +1 controle negativo $\mathrm{x} 3$ repetições $\mathrm{x} 60$ sementes).

Para os testes de citogenotoxicidade foi utilizado o DIC, seguindo os mesmos esquemas fatoriais utilizados para os testes de fitotoxicidade com as amostras de água e extratos dos sedimentos considerando-se os mesmos fatores de estudo. Para o IM foram analisados 30 campos em três meristemas apicais de raízes (indivíduos) lotados em três lâminas de cada tratamento para cada coleta, totalizando 1.800 sementes das amostras de água e 930 sementes dos extratos de sedimento (30 campos $\mathrm{x}$ número de tratamentos $\mathrm{x} 10$ coletas).

A análise da frequência de AC foi realizada em 15 campos seguindo os mesmos padrões adotados para o IM, totalizando 900 sementes das amostras de água e 465 dos extratos de 
sedimento ( 15 campos $\mathrm{x}$ número de tratamentos $\mathrm{x} 10$ coletas). Foram avaliadas cerca de 3.000 células/tratamento para obtenção do IM e da frequência de AC. Os dados de todos os testes foram submetidos à análise de variância (ANOVA) e as médias foram comparadas pelo teste de Scott-Knott a 0,05 de significância.

\section{Resultados e Discussão}

As águas do Córrego do Pântano são utilizadas para abastecimento público (apenas na sua nascente) dessedentação de animais e irrigação de hortaliças. Com isto, espera-se que as características físico-químicas de suas águas atendam no mínimo aos padrões propostos para corpos d'água Classe III. Assim, para fins de comparação dos nossos resultados das análises químicas, foram utilizados os padrões de qualidade de corpos de água da Classe III (Tabela 1). Ressalta-se, também, que a água desse córrego é destinada para recreação de contato primário e aquicultura, usos esses permitidos apenas aos corpos d'água classes superiores.

As concentrações de $\mathrm{Cd}$ e $\mathrm{Pb}$ ultrapassaram os padrões para corpos d'água de Classe III no início da época chuvosa

Tabela 1. Características físico-químicas avaliadas nas águas dos diferentes pontos e épocas de coleta e sua comparação com os padrões de qualidade de águas de corpos de Classe III, segundo a resolução CONAMA $\mathrm{n}^{\circ} 357$ (Brasil, 2005)

\begin{tabular}{|c|c|c|c|c|c|c|}
\hline & \multirow{2}{*}{$\begin{array}{l}\text { Padrões - } \\
\text { Classe III }\end{array}$} & \multicolumn{5}{|c|}{ Ponto de coleta } \\
\hline & & P1 & P2 & P3 & P4 & P5 \\
\hline \multicolumn{7}{|c|}{ Outubro-Novembro } \\
\hline $\mathrm{Cd}^{*}$ & 0,01 & n.d. & $0,0128^{*}$ & $0,0114^{*}$ & 0,0096 & $0,0108^{*}$ \\
\hline $\mathrm{Zn}$ & 5 & 0,1677 & 0,0169 & 0,0166 & 0,0181 & 0,0203 \\
\hline $\mathrm{Pb}^{\star}$ & 0,033 & $0,0904^{*}$ & $0,0870 *$ & $0,1093^{*}$ & 0,0956 * & $0,0887^{*}$ \\
\hline CE & - & 27,37 & 114,40 & 110,80 & 415,80 & 365,50 \\
\hline $\mathrm{pH}^{*}$ & $6,0-9,0$ & $5,4^{*}$ & 6,3 & 6,3 & 6,7 & 6,7 \\
\hline \multicolumn{7}{|c|}{ Dezembro-Janeiro } \\
\hline $\mathrm{Cd}^{*}$ & 0,01 & 0,0034 & 0,0069 & $0,0125^{\star}$ & 0,0049 & 0,0032 \\
\hline $\mathrm{Zn}$ & 5 & 0,0069 & 0,2591 & 0,2367 & 0,2483 & 0,2141 \\
\hline $\mathrm{Pb} *$ & 0,033 & $0,0593^{*}$ & $0,1166^{\star}$ & $0,1143^{*}$ & $0,0919 *$ & $0,0471^{*}$ \\
\hline CE & - & 28,15 & 114,95 & 105,65 & 243,35 & 243,60 \\
\hline $\mathrm{pH}^{*}$ & $6,0-9,0$ & $5,4^{*}$ & 6,1 & 6,4 & 6,8 & 6,7 \\
\hline \multicolumn{7}{|c|}{ Fevereiro-Março } \\
\hline $\mathrm{Cd}$ & 0,01 & 0,0049 & 0,0028 & 0,0018 & 0,0027 & 0,0047 \\
\hline$Z n$ & 5 & 0,0943 & 0,0746 & 0,0081 & 0,1314 & 0,1371 \\
\hline $\mathrm{Pb}$ & 0,033 & n.d. & n.d. & n.d. & n.d. & 0,0165 \\
\hline CE & - & 17,07 & 68,35 & 53,90 & 385,75 & 90,65 \\
\hline $\mathrm{pH}^{*}$ & $6,0-9,0$ & $5,8^{\star}$ & 7,0 & 7,0 & 7,4 & 7,1 \\
\hline \multicolumn{7}{|c|}{ Abril-Maio } \\
\hline $\mathrm{Cd}$ & 0,01 & 0,0020 & 0,0013 & 0,0015 & 0,0013 & 0,0006 \\
\hline $\mathrm{Zn}$ & 5 & 0,0578 & 0,0673 & 0,1291 & 0,0706 & 0,0540 \\
\hline $\mathrm{Pb}$ & 0,033 & 0,0162 & n.d. & n.d. & 0,0058 & n.d. \\
\hline CE & - & 11,16 & 81,95 & 43,90 & 261,00 & 52,90 \\
\hline $\mathrm{pH}^{*}$ & $6,0-9,0$ & $5,8^{*}$ & 8,0 & 6,8 & 7,5 & 7,0 \\
\hline \multicolumn{7}{|c|}{ Junho-Julho } \\
\hline $\mathrm{Cd}$ & 0,01 & n.d. & 0,0007 & 0,0001 & 0,0005 & 0,0005 \\
\hline $\mathrm{Zn}$ & 5 & 0,0083 & 0,0132 & 0,0759 & 0,0024 & 0,0489 \\
\hline $\mathrm{Pb}$ & 0,033 & 0,0056 & n.d. & n.d. & n.d. & n.d. \\
\hline CE & - & 13,31 & 134,75 & 61,75 & 234,00 & 101,45 \\
\hline $\mathrm{pH}^{*}$ & $6,0-9,0$ & $5,3^{*}$ & 6,9 & 6,5 & 7,2 & 6,7 \\
\hline
\end{tabular}

sendo que o $\mathrm{Pb}$ atingiu mais que o triplo do valor padrão. $\mathrm{O}$ enquadramento de corpos d'água nas classes propostas pela resolução CONAMA n 357 (Brasil, 2005) é efetivo somente quando todas as características atendem aos padrões. Portanto, com base nos dados obtidos neste trabalho o Córrego do Pântano não se apresenta em consonância com a legislação vigente, embora outros parâmetros da resolução ainda devam ser avaliados.

As maiores concentrações de $\mathrm{Cd}$ foram encontradas nos pontos de coleta contaminados predominantemente por efluente doméstico e sua presença nesse tipo de resíduo também é relatada por Singh et al. (2005). As elevadas concentrações de $\mathrm{Pb}$ foram evidenciadas em todo o corpo d'água no período de chuvas, inclusive na mina d'água utilizada para abastecimento público. As concentrações de $\mathrm{Zn}$ não ultrapassaram os padrões para corpos d'água da Classe III em nenhum ponto ou época de coleta.

As redes de drenagem de superfícies urbanas são conhecidas como fontes de metais e outros contaminantes (Bollmann $\&$ Marques, 2006). Considerando que os metais podem ser arrastados para o córrego pelo escoamento superficial gerado com as precipitações pluviométricas, é possível ter ocorrido um acúmulo desses na superfície da microbacia durante a época de estiagem e durante o período de chuvas (com início em Outubro de 2010), esses metais provavelmente foram arrastados para o córrego resultando no aumento das suas concentrações (Tabela 1).

Foram observados, de forma geral, um aumento da condutividade elétrica no sentido montante-jusante do córrego e valores destacadamente maiores nos pontos P2 e P4 (Tabela 1) sugerindo que a inserção de efluentes domésticos no $P 2$ e de efluentes têxteis no $\mathrm{P} 4$ aumentou a salinidade da água nesses locais. Ambientes contaminados com efluentes domésticos tendem a ter a salinidade aumentada (Bazai \& Achakzai, 2006). Os altos valores de condutividade elétrica no ponto $P 4$ são influenciados, provavelmente, pelo efluente tratado das indústrias têxteis.

Para os sedimentos não se observou contaminação pelos metais estudados, nem se encontrou uma legislação que considere os sedimentos como um micro-habitat (para organismos sésseis e bentônicos, por exemplo) importante para o ecossistema aquático do ponto de vista ecológico e ecotoxicológico. Portanto, neste trabalho os padrões de qualidade adotados foram baseados na resolução CONAMA n. 344 (Brasil, 2004) que estabelece diretrizes para avaliação dos sedimentos dragados no território brasileiro e dispostos no ambiente como resíduos sólidos (Tabela 2). Nesta resolução foram adotados, como referência, os critérios de qualidade do Nível 1 que determinam o limiar abaixo do qual se prevê baixa probabilidade de ocorrerem efeitos adversos à biota.

As concentrações de metais no sedimento não ultrapassaram os limites propostos pela legislação em nenhum ponto e em época alguma de coleta. Os teores de matéria orgânica ultrapassaram o limite proposto apenas nos períodos mais secos. Esta variação temporal pode estar relacionada com a diminuição da vazão do córrego no período de estiagem e ao aumento da concentração relativa de efluentes domésticos. 
Tabela 2. Concentrações de metais e matéria orgânica presentes nas amostras de sedimentos dos diferentes pontos e épocas de coleta e sua comparação com os padrões estabelecidos para o Nível 1 da resolução CONAMA n 344 (Brasil, 2004)

\begin{tabular}{|c|c|c|c|c|}
\hline & \multirow{2}{*}{ Padrões - Nível 1} & \multicolumn{3}{|c|}{ Ponto de coleta } \\
\hline & & P2 & P3 & P4 \\
\hline \multicolumn{5}{|c|}{ Outubro-Novembro } \\
\hline $\mathrm{Cd}$ & 0,6 & 0,066 & 0,083 & 0,113 \\
\hline $\mathrm{Pb}$ & 35,0 & 3,156 & 3,313 & 4,014 \\
\hline $\mathrm{Zn}$ & 123,0 & 9,851 & 11,924 & 15,091 \\
\hline $\mathrm{Ni}$ & 18,0 & 1,703 & 1,717 & 1,608 \\
\hline MO & $<10$ & 3,500 & 5,440 & 7,000 \\
\hline \multicolumn{5}{|c|}{ Dezembro-Janeiro } \\
\hline $\mathrm{Cd}$ & 0,6 & 0,124 & 0,148 & 0,168 \\
\hline $\mathrm{Pb}$ & 35,0 & 5,546 & 4,284 & 3,625 \\
\hline $\mathrm{Zn}$ & 123,0 & 15,455 & 9,661 & 14,606 \\
\hline $\mathrm{Ni}$ & 18,0 & 2,450 & 2,011 & 1,544 \\
\hline MO & $<10$ & 5,450 & 2,610 & 6,060 \\
\hline \multicolumn{5}{|c|}{ Fevereiro-Março } \\
\hline $\mathrm{Cd}$ & 0,6 & 0,193 & 0,178 & 0,195 \\
\hline $\mathrm{Pb}$ & 35,0 & 2,930 & 4,979 & 3,241 \\
\hline $\mathrm{Zn}$ & 123,0 & 6,208 & 11,319 & 10,361 \\
\hline $\mathrm{Ni}$ & 18,0 & 1,706 & 1,951 & 1,696 \\
\hline $\mathrm{MO}^{*}$ & $<10$ & $13,39^{*}$ & 11,250 & 9,550 \\
\hline \multicolumn{5}{|c|}{ Abril-Maio } \\
\hline $\mathrm{Cd}$ & 0,6 & 0,206 & 0,215 & 0,212 \\
\hline $\mathrm{Pb}$ & 35,0 & 2,966 & 1,759 & 2,418 \\
\hline $\mathrm{Zn}$ & 123,0 & 10,941 & 5,226 & 7,935 \\
\hline $\mathrm{Ni}$ & 18,0 & 1,789 & 1,064 & 1,432 \\
\hline $\mathrm{MO}^{*}$ & $<10$ & 9,270 & $28,22^{*}$ & 7,820 \\
\hline \multicolumn{5}{|c|}{ Junho-Julho } \\
\hline $\mathrm{Cd}$ & 0,6 & 0,189 & 0,202 & 0,224 \\
\hline $\mathrm{Pb}$ & 35,0 & 4,393 & 2,747 & 1,997 \\
\hline $\mathrm{Zn}$ & 123,0 & 16,348 & 9,261 & 7,901 \\
\hline $\mathrm{Ni}$ & 18,0 & 2,537 & 1,611 & 1,667 \\
\hline $\mathrm{MO}$ * & $<10$ & $10,79 *$ & 6,160 & 6,610 \\
\hline
\end{tabular}

Cd - Cádmio (mg L-1); Pb - Chumbo (mg L-1); Zn - Zinco (mg L-1); Ni - Níquel (mg L-1); $M 0$ Matéria Orgânica (\%); ( ${ }^{*}$ ) Não atendimento aos padrões de qualidade da resolução do CONAMA 344 (Brasil, 2004)

As características utilizadas na avaliação da toxicidade não apresentaram interação significativa entre os fatores tratamento (pontos de coleta + controle negativo) e tempo (épocas de coleta) à exceção do comprimento de raízes (CR) de L. sativa exposta às amostras de água (Tabela 3 ). Portanto, o efeito das amostras de água sobre o CR é resultado da combinação dos efeitos dos tratamentos e da época de coleta e por isso os resultados para este parâmetro serão expostos separadamente dos demais avaliados.

As águas de todos os pontos de coleta reduziram a taxa de germinação (TG) de $L$. sativa (Tabela 4). As sementes de $L$. sativa possuem uma grande superfície de contato (Andrade et al., 2010), pequeno tamanho, massa e, consequentemente, baixa quantidade de endosperma disponível. O endosperma age como mecanismo de resistência da germinação às condições ambientais adversas (Bisognin et al., 2005). O tegumento da semente e o endosperma também protegem o embrião contra a ação tóxica de metais ( $\mathrm{Li}$ et al., 2005) e a permeabilidade varia entre espécies (Kranner \& Colville, 2011). Assim, sementes pobres em endosperma se tornam mais suscetíveis às condições do meio principalmente nos primeiros estágios de desenvolvimento, como as da espécie empregada neste estudo.

Tabela 4. Efeito das amostras de água e dos extratos aquosos dos sedimentos sobre a Taxa de Germinação (TG), Comprimento de Raiz (CR), Biomassa Fresca da Plântula (MF) e Biomassa Seca Total (MS)

\begin{tabular}{|c|c|c|c|c|}
\hline & \multirow{2}{*}{ TG (\%) } & \multirow{2}{*}{ CR (cm) } & MF & MS \\
\hline & & & \multicolumn{2}{|c|}{ (mg) } \\
\hline & \multicolumn{4}{|c|}{ Amostras de água } \\
\hline Controle & 94,31 a & i.s. & $5,873 \mathrm{a}$ & $7,655 \mathrm{a}$ \\
\hline P1 & $91,32 b$ & i.s. & $5,707 \mathrm{a}$ & $7,793 \mathrm{a}$ \\
\hline P2 & $91,27 \mathrm{~b}$ & i.s. & $5,807 \mathrm{a}$ & $7,673 \mathrm{a}$ \\
\hline P3 & $91,88 \mathrm{~b}$ & i.s. & $5,613 \mathrm{a}$ & $7,637 \mathrm{a}$ \\
\hline P4 & $89,54 \mathrm{~b}$ & i.s. & $5,640 \mathrm{a}$ & $7,397 \mathrm{a}$ \\
\hline \multirow[t]{2}{*}{ P5 } & $89,83 \mathrm{~b}$ & i.s. & $5,847 \mathrm{a}$ & $7,697 \mathrm{a}$ \\
\hline & \multicolumn{4}{|c|}{ Extratos aquosos dos sedimentos } \\
\hline Controle & $83,89 \mathrm{a}$ & $0,977 \mathrm{~b}$ & $6,280 \mathrm{a}$ & $7,467 \mathrm{a}$ \\
\hline P1 & - & - & - & - \\
\hline P2 & $69,00 \mathrm{~b}$ & $1,435 \mathrm{a}$ & $5,788 \mathrm{~b}$ & $7,033 b$ \\
\hline P3 & 70,72 b & $1,405 a$ & $5,838 \mathrm{~b}$ & $7,013 b$ \\
\hline P4 & $66,11 b$ & $1,347 \mathrm{a}$ & $5,798 b$ & $7,020 \mathrm{~b}$ \\
\hline P5 & - & - & - & - \\
\hline
\end{tabular}

Médias seguidas da mesma letra nas colunas não diferem entre si pelo teste de Scott-Knott a 0,05 de significância; P1, P2, P3, P4 e P5 - pontos de coleta de 1 a 5, respectivamente "i.s." - interação significativa

A tolerância ao estresse por metais e as concentrações que fazem deles contaminantes ou micronutrientes variam entre espécies (Kranner \& Colville, 2011). Em baixas concentrações alguns metais podem ser essenciais mas em altas concentrações apresentam efeito fitotóxico. Li et al. (2005) avaliaram a toxicidade de $\mathrm{Cd}^{2+}, \mathrm{Pb}^{2+} \mathrm{e} \mathrm{Zn}^{2+}$ sobre a germinação de Arabdopsis thaliana L. e observaram que todos os metais apresentaram fitotoxicidade, sendo Cd o mais tóxico. A inibição da TG em L. sativa pelo Cd foi relatada também por Corrêa et al. (2006). Lefevre et al. (2009) não observaram efeito direto do $\mathrm{Cd}$ sobre a germinação de Dorycnium pentaphyllum Scop., mas sim sobre a embebição das sementes. O Cd é frequentemente

Tabela 3. Efeitos isolados e interações dos fatores tratamento e tempo das amostras de água e dos extratos aquosos dos sedimentos do Córrego do Pântano sobre a taxa de germinação (TG), comprimento de raiz (CR), biomassa fresca das plântulas (MF), biomassa seca total (MS), índice mitótico (IM) e frequência de anormalidades cromossômicas (AC)

\begin{tabular}{|c|c|c|c|c|c|c|}
\hline \multirow[t]{2}{*}{ Fatores de estudo } & \multicolumn{6}{|c|}{ P-valor } \\
\hline & TG & CR & MF & MS & IM & AC \\
\hline Tratamento & $0,0020 *$ & $<0,0001^{\star}$ & 0,5298 & 0,3972 & $0,0015^{\star}$ & 0,9646 \\
\hline Interação tratamento x tempo & 0,3108 & $<0,0001^{*}$ & 0,1547 & 0,1591 & 0,6767 & 0,4642 \\
\hline & \multicolumn{6}{|c|}{ Extratos aquosos dos sedimentos } \\
\hline Tratamento & $0,0001^{*}$ & $0,0156^{*}$ & $<0,0001^{\star}$ & $0,0069 *$ & 0,1511 & 0,7474 \\
\hline
\end{tabular}

${ }^{\star}{ }^{\star}$ ) Efeitos significativos segundo 0 teste de Scott-Knott a 0,05 de significância 
encontrado em águas residuárias e em resíduos da produção de ferro, aço e do recobrimento de produtos metálicos (Cardoso \& Chasin, 2001).

A barreira formada pela tegumento e o endosperma das sementes pode fazer com que a toxicidade do $\mathrm{Pb}$ sobre a TG não seja observada somente na forma de inibição mas também como um atraso no processo de germinação (Wierzbicka \& Obidzinska, 1998). Munzuroglu \& Geckil (2002) também observaram inibição da TG em Cucumis sativus L. e Triticum aestivum $\mathrm{L}$. expostos a altas concentrações de $\mathrm{Pb}$. A redução da TG no ponto P1 também pode ter relação com as altas concentrações de $\mathrm{Pb}$ observadas no período chuvoso, em novembro de 2010 (Tabela 1).

O Zn é conhecido como um micronutriente para organismos vegetais e seu potencial fitotóxico geralmente é evidenciado apenas em concentrações muito altas (Kranner \& Colville, 2011). Para este metal os níveis observados nas amostras de água não ultrapassaram os padrões para corpos d'água Classe III.

Os metais são parte de uma série de poluentes oriundos do escoamento superficial (Bollmann \& Marques, 2006) e, de forma geral, as concentrações de metais obtidos foram menores em épocas de estiagem e maiores nas épocas chuvosas (Tabela 1). O escoamento superficial carreia esses contaminantes do ambiente urbano para as microbacias de drenagem aumentando sua concentração, o que pode estar relacionado à baixa TG observada no período com maior índice pluviométrico (Figura 2).

Efluentes domésticos e industriais em altas concentrações inibem a germinação em $L$. sativa, aumentando a salinidade pelo incremento de íons minerais que afetam a osmorregulação, levando à falência organelas responsáveis por essa função (Bazai \& Achakzai, 2006). Andrade et al. (2010) relataram que os íons cloreto presentes em efluentes domésticos e industriais podem causar inibição da germinação e do crescimento de plântulas de L. sativa. A condutividade elétrica da água está estreitamente relacionada com a quantidade de íons nela dissolvidos e por isso reflete sua salinidade. Aumentos nos valores de condutividade elétrica foram observados principalmente nos pontos $\mathrm{P} 2$ e P4, tal como nos meses chuvosos (Tabela 1 ).

Assim como para a água, os extratos dos sedimentos do Córrego do Pântano reduziram significativamente a TG de L. sativa, demonstrando a fitotoxicidade dessas amostras. A observação de efeito tóxico do sedimento sobre $L$. sativa frente às baixas concentrações de metais encontradas pode estar relacionada com interações aditivas ou sinérgicas proporcionadas pela extração aquosa, transformando ou biodisponibilizando esses ou outros contaminantes (Wilke et al., 2008) não quantificados neste trabalho.

Além de metais pesados vários contaminantes com potencial fitotóxico foram encontrados em estudos com solos e com sedimentos de corpos d'água em áreas urbanizadas, como hidrocarbonetos aromáticos policíclicos (HAP), compostos organoclorados e outros poluentes orgânicos (Garcia et al., 2009). Comumente, esses contaminantes são relatados em águas do escoamento superficial pela lavagem do solo de áreas agrícolas e do asfalto (Bollmann \& Marques, 2006) e em efluentes de indústrias têxteis (Garcia et al., 2009).
A.

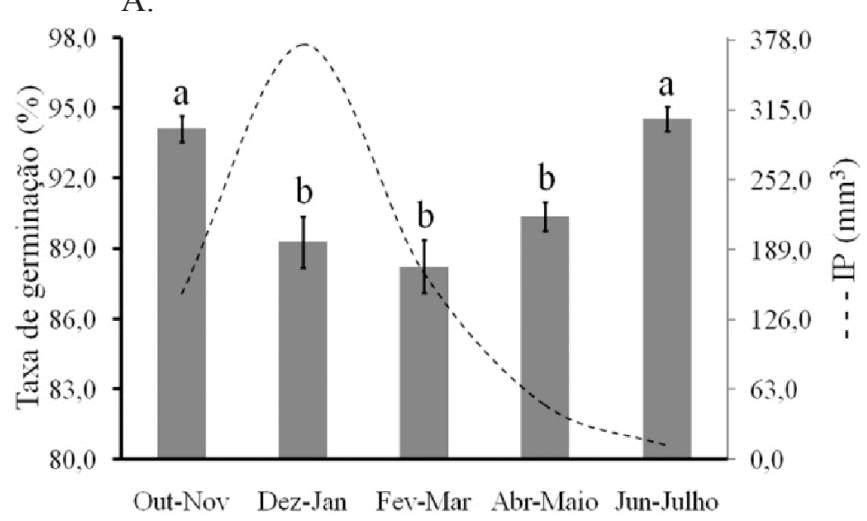

B.

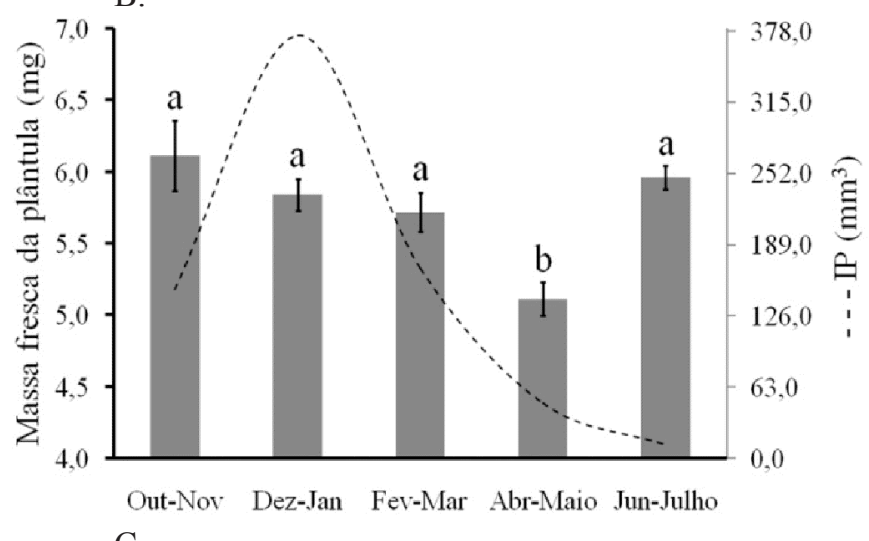

C.

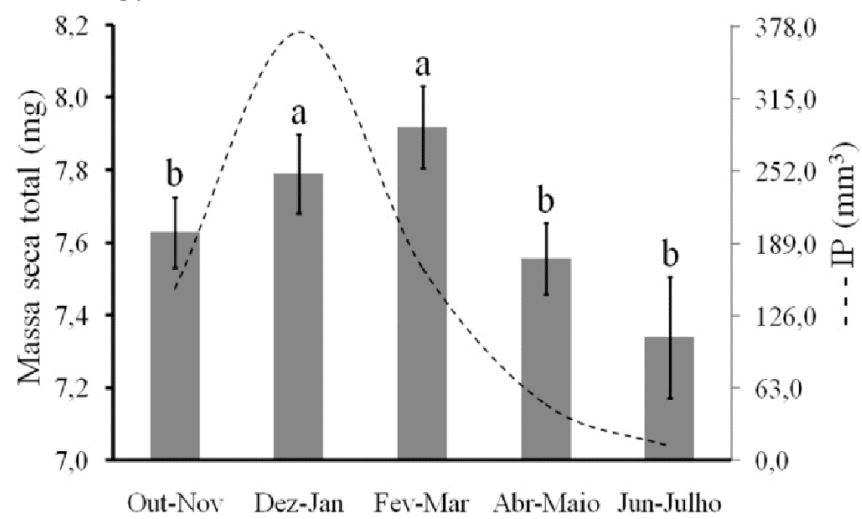

As médias seguidas da mesma letra não diferem entre si pelo teste de Scott-Knott a $5 \%$ de significância. IP - Índice pluviométrico médio bimestral. Barra: erro padrão

Figura 2. Variação temporal da fitotoxicidade das amostras de água sobre a taxa de germinação (A), a biomassa fresca da plântula (B) e a biomassa seca total $(\mathrm{C})$

Tal como para as amostras de água, a baixa TG pode ser decorrente da salinidade dos extratos dos sedimentos (Bazai $\&$ Achakzai, 2006). De acordo com Baumgarten et al. (2001), na área logo abaixo da superfície dos sedimentos as condições redutoras são mais frequentes e intensas que na coluna d'água e favorecem a redissolução de muitos íons. Esses íons passam a fazer parte da água intersticial atuando como reservatório de espécies químicas dissolvidas que podem migrar para a coluna da água. Esses autores afirmam também que a turbulência e a hidrodinâmica aumentam os intercâmbios químicos entre a água e o sedimento, sobretudo em corpos d'água com pouca profundidade. Assim, é provável que os sedimentos apresentem 
alta salinidade e sejam responsáveis por parte dos altos valores de condutividade elétrica observados nas amostras de água.

A água do Córrego do Pântano não apresentou toxicidade sobre o CR de L. sativa e foi evidenciado um estímulo deste parâmetro pelas águas coletadas a partir do ponto P2 (Tabela 5). Este estímulo não foi observado para a água do ponto P1. Foi constatada interação significativa entre os fatores Tratamento e Tempo sobre CR.

Tabela 5. Comparação de médias do comprimento de raiz $(\mathrm{cm})$ de $L$. sativa exposta às amostras de água para os diferentes pontos de coleta avaliados, nas diferentes épocas de coleta

\begin{tabular}{lccccc}
\hline & Out-Nov & Dez-Jan & Fev-Mar & Abr-Maio & Jun-Julho \\
Controle & $1,183 \mathrm{~b}$ & $1,292 \mathrm{~b}$ & $1,096 \mathrm{~b}$ & $1,028 \mathrm{~b}$ & $1,258 \mathrm{~b}$ \\
P1 & $1,178 \mathrm{~b}$ & $1,380 \mathrm{~b}$ & $1,105 \mathrm{~b}$ & $1,204 \mathrm{~b}$ & $1,146 \mathrm{~b}$ \\
P2 & $1,882 \mathrm{a}$ & $1,929 \mathrm{a}$ & $1,416 \mathrm{a}$ & $1,839 \mathrm{a}$ & $1,684 \mathrm{a}$ \\
P3 & $2,077 \mathrm{a}$ & $2,201 \mathrm{a}$ & $1,627 \mathrm{a}$ & $1,817 \mathrm{a}$ & $1,323 \mathrm{~b}$ \\
P4 & $1,906 \mathrm{a}$ & $2,234 \mathrm{a}$ & $1,138 \mathrm{~b}$ & $1,682 \mathrm{a}$ & $1,225 \mathrm{~b}$ \\
P5 & $1,927 \mathrm{a}$ & $2,053 \mathrm{a}$ & $1,660 \mathrm{a}$ & $1,647 \mathrm{a}$ & $1,795 \mathrm{a}$ \\
\hline
\end{tabular}

Médias seguidas da mesma letra nas colunas não diferem entre si pelo teste de Scott-Knott a 0,05 de significância. P1, P2, P3, P4 e P5 - Pontos de coleta de 1 a 5, respectivamente

Efeitos estimulantes foram relatados por Tigini et al. (2011) e Alvim et al. (2011) para plantas expostas a efluentes domésticos e industriais. Esses autores argumentam que a carga orgânica advinda principalmente do efluente doméstico pode ter proporcionado uma oferta maior de nutrientes que contribuem para o aumento do CR. Efluentes têxteis com elevada carga orgânica também estimularam o CR em estudos com os modelos Brassica rapa L. (Rehman et al., 2009) e Allium cepa L. (Alvim et al., 2011).

No período de estiagem (junho-julho) os pontos P3 e P4 não estimularam o crescimento das raízes de L. sativa (Figura 3) provavelmente pela diminuição do regime de chuvas e da

Comprimento de raiz $(\mathrm{cm})$

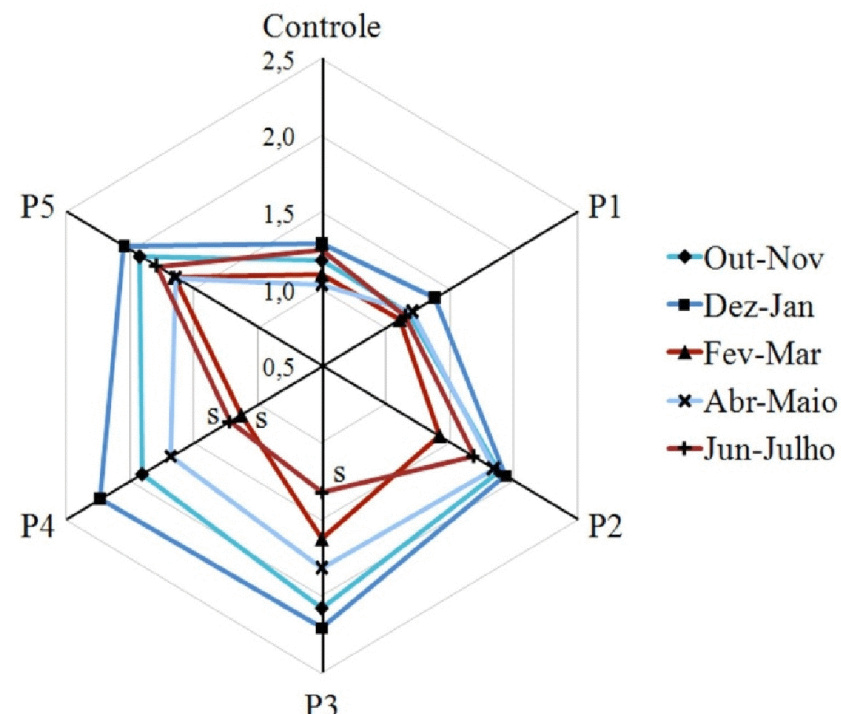

As épocas de coleta acompanhadas pela letra "s" diferem significativamente das demais para 0 ponto de coleta, segundo o teste de Scott-Knott a 0,05 de significância. P1, P2, P3, P4 e P5 - Pontos de coleta de 1 a 5 , respectivamente

Figura 3. Variação temporal do efeito das amostras de água sobre o comprimento de raiz $(\mathrm{cm})$ de $L$. sativa nos diferentes pontos de coleta consequente disponibilização de nutrientes e matéria orgânica proveniente dos despejos domésticos e industriais, casos em que o efeito estimulante pode ter sido sobrepujado pelo aumento relativo da concentração de contaminantes não quantificados e seus respectivos efeitos tóxicos, principalmente no ponto P4 que sofre influência direta do despejo de efluentes têxteis.

O mesmo efeito estimulante foi observado para os extratos dos sedimentos (Tabela 4). Resultados semelhantes foram obtidos por Czerniawska-Kusza \& Kusza (2011) que avaliaram a fitotoxicidade de sedimentos de águas de um reservatório contaminado por metais e nutrientes e observaram efeito estimulante do crescimento para as três espécies estudadas (Sorgum saccharatum L. Moench, Sinapis Alba L. e Lepidium sativum L.). Algumas hipóteses foram propostas para explicar este estímulo, como a estabilidade ou a insolubilidade dos contaminantes detectados, sua associação com outras partículas ou mesmo um falso negativo gerado pela biodisponibilização de nutrientes adsorvidos na matéria orgânica do sedimento.

O estímulo do $\mathrm{CR}$ dos extratos dos sedimentos foi observado principalmente nos meses chuvosos (Figura 4A) sugerindo que, neste período, o aumento da vazão do córrego proporcionou disponibilização química de nutrientes. Adicionalmente, a diminuição da turbulência nos meses secos pode ter reduzido a disponibilidade de nutrientes em detrimento de contaminantes eventualmente presentes e que tiveram sua concentração aumentada e então passaram a exercer efeito tóxico mais significativo.

A.

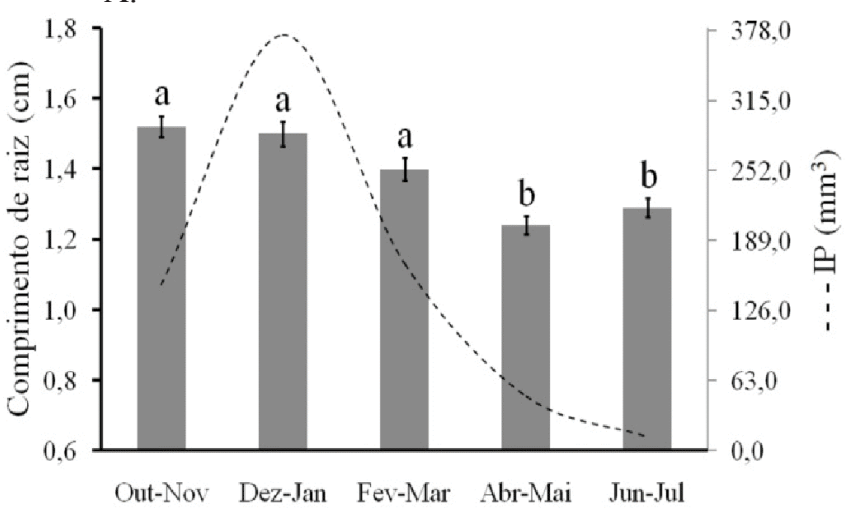

B.

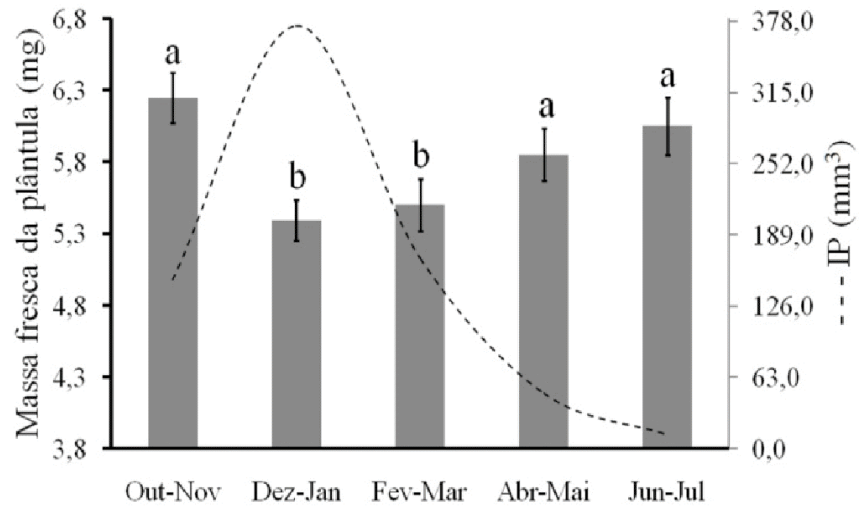

As médias seguidas da mesma letra não diferem entre si pelo teste de Scott-Knott a 0,05 de significância. IP - Índice pluviométrico médio bimestral. Barra: erro padrão

Figura 4. Variação temporal da fitotoxicidade dos extratos aquosos dos sedimentos sobre o comprimento de raiz (A) e a biomassa fresca das plântulas (B) 
A biomassa fresca das plântulas (MF) e a biomassa seca total (MS) não foram reduzidas pelas águas dos diferentes pontos de coleta (Tabela 4) mas foi observada variação temporal significativa que indica maior toxicidade das águas coletadas em épocas secas (Figuras 2B e 2C). No entanto, o contrário foi constatado para os extratos dos sedimentos em que a disponibilização de contaminantes a partir do sedimento e a salinidade também podem ter sido responsáveis pela redução da MF.

Como o observado para a TG, a MF foi reduzida pelos extratos dos sedimentos principalmente nos meses chuvosos nos quais foram observados os maiores valores de condutividade elétrica (Figura 4B). O aumento da salinidade pode afetar a MF das plântulas por prejudicar a permeabilidade aos íons $\mathrm{Na}^{+} \mathrm{e}$ $\mathrm{K}^{+}$, que são fatores importantes no ganho de biomassa e seu influxo por meio de vias metabólicas. De acordo com Wimmer et al. (2003) a absorção de $\mathrm{Ca}^{2+}$ também é prejudicada pela salinidade em razão de causar desestabilização das membranas.

De acordo com os resultados obtidos para o controle positivo, a sensibilidade do organismo-teste foi considerada adequada para o ensaio citogenético. As amostras de água de todos os pontos de coleta reduziram a divisão celular em $L$. sativa (Tabela 6). Conforme Fernandes et al. (2007) o Índice Mitótico (IM) é um parâmetro confiável para determinar a presença de compostos citotóxicos no ambiente e indicado para o biomonitoramento dos níveis de poluição.

Tabela 6. Efeito das amostras de água e dos extratos aquosos dos sedimentos dos diferentes pontos de coleta sobre o índice mitótico (IM) e frequência de anormalidades cromossômicas (AC)

\begin{tabular}{lcccc}
\hline & \multicolumn{2}{c}{ Amostras de água } & \multicolumn{2}{c}{ Extratos aquosos dos sedimentos } \\
\cline { 2 - 5 } & IM & AC & IM & AC \\
\cline { 2 - 5 } & & & $\mathbf{( \% )}$ & \\
Controle & $51,09 \mathrm{a}$ & $4,24 \mathrm{a}$ & $48,30 \mathrm{a}$ & $4,91 \mathrm{a}$ \\
P1 & $47,01 \mathrm{~b}$ & $4,05 \mathrm{a}$ & - & - \\
P2 & $45,50 \mathrm{~b}$ & $3,90 \mathrm{a}$ & $44,45 \mathrm{a}$ & $6,14 \mathrm{a}$ \\
P3 & $46,10 \mathrm{~b}$ & $4,26 \mathrm{a}$ & $47,25 \mathrm{a}$ & $6,35 \mathrm{a}$ \\
P4 & $47,66 \mathrm{~b}$ & $4,22 \mathrm{a}$ & $45,71 \mathrm{a}$ & $6,57 \mathrm{a}$ \\
P5 & $47,39 \mathrm{~b}$ & $4,24 \mathrm{a}$ & - & - \\
\hline
\end{tabular}

Médias seguidas da mesma letra nas colunas não diferem entre si pelo teste de Scott-Knott a 0,05 de significância; P1, P2, P3, P4 e P5 - pontos de coleta de 1 a 5, respectivamente

Os metais e outros compostos encontrados em efluentes industriais apresentam efeitos citotóxicos e genotóxicos, como a morte celular e a inibição da síntese de DNA e proteínas associadas, que podem ser observados na forma de redução do IM (Leme \& Marin-Morales, 2009). Não foi observado efeito citotóxico dos extratos dos sedimentos sobre o IM (Tabela 6).

A.

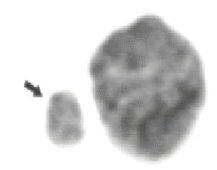

B.

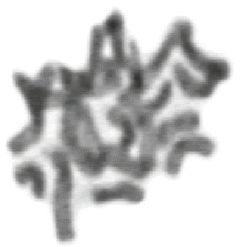

C.

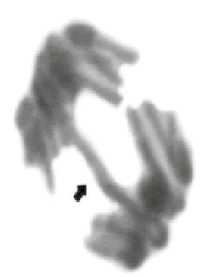

A variação temporal do IM foi significativa para as amostras de água e para os extratos de sedimento porém não foi constatada relação com o regime pluviométrico das diferentes épocas estudadas (Figura 5A). O CR e o IM geralmente são características positivamente correlacionadas e o contraste entre os resultados obtidos pode estar relacionado ao fato de que, nos primeiros estádios de desenvolvimento da planta, o CR ocorre pela expansão celular e não pela taxa de divisão (Maila \& Cloete, 2002).

A.

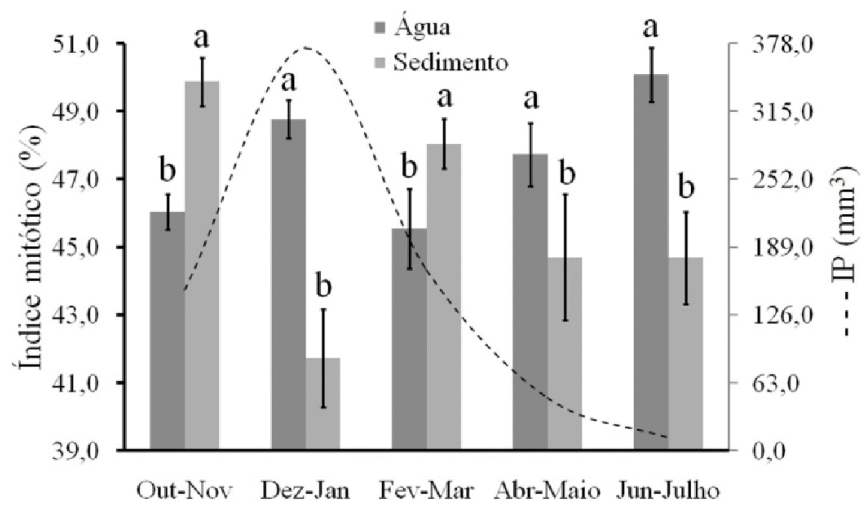

B.

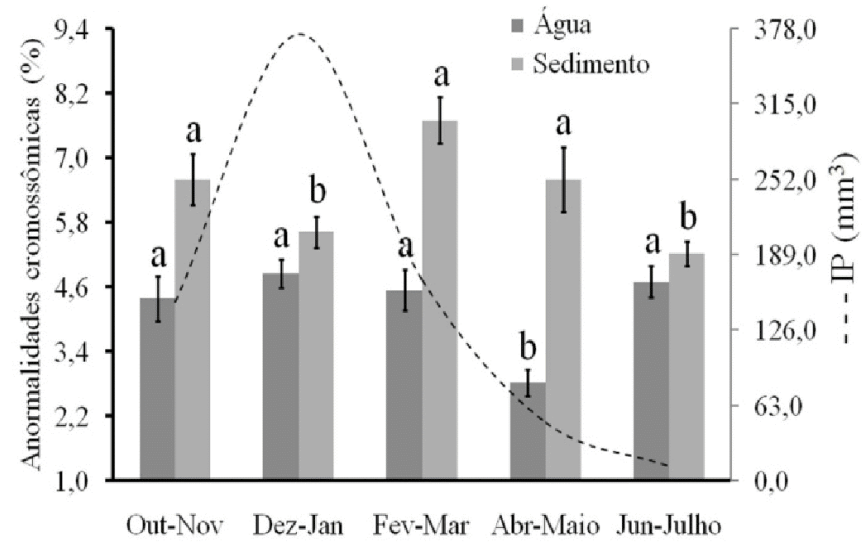

As médias seguidas de médias letras não diferem entre si pelo teste de Scott-Knott a 0,05 de significância. IP - Índice pluviométrico médio bimestral. Barra: erro padrão

Figura 5. Variação temporal da genotoxicidade das amostras de água e dos extratos aquosos dos sedimentos sobre o índice mitótico $(A)$ e a frequência de anormalidades cromossômicas (B) em L. sativa

A presença de anormalidades cromossômicas (AC) não foi alterada pelas amostras de água nem pelos extratos dos sedimentos (Tabela 6). De acordo com Leme \& Marin-Morales (2009) as AC são transformações que ocorrem na estrutura dos cromossomos ou em todo o complemento cromossômico, pela

Figura 6. Tipos de anormalidades cromossômicas investigadas. Micronúcleo (A); Metáfase (B, C); Ponte cromossômica (em anáfase ou telófase) (C); Cromossomos perdidos (caso, em conjunto com uma ponte telofásica) (D); Cromossomos aderentes (Stickiness) (E). Barra de escala: $5 \mu \mathrm{m}$ 
ação de agentes químicos ou físicos ou mesmo espontaneamente. Portanto, o resultado obtido sugere que as amostras de água não estimularam a ocorrência de AC pressupondo que a frequência observada ocorre de forma espontânea. As AC investigadas estão descritas na Figura 6.

$\mathrm{O} \mathrm{IM}$, tanto quanto a frequência de $\mathrm{AC}$, não apresentou relação com o regime pluviométrico (Figura 5B).

No estudo conduzido por Alvim et al. (2011) relativo à genotoxicidade dos efluentes das indústrias têxteis dispostos no Córrego do Pântano, os efluentes não tratados apresentaram elevado efeito genotóxico, embora também se tenha evidenciado efeito do efluente tratado sobre esta característica.

\section{Conclusões}

1. O Córrego do Pântano não se enquadra nos padrões propostos para corpos d'água de Classe III da resolução CONAMA $n^{\circ} 357 / 2005$, sugerindo a necessidade de adoção de medidas de recuperação da qualidade da água.

2. A água e o sedimento apresentam fitotoxicidade sobre Lactuca sativa e as concentrações de metais e de salinidade podem ter contribuído para este efeito, juntamente com outros toxicantes não analisados.

3. O sedimento apresenta maior fitotoxicidade que a água reduzindo a taxa de germinação e a produção de biomassa das plântulas de Lactuca sativa enquanto a água reduz apenas a taxa de germinação. Água e sedimento não apresentam fitotoxicidade sobre o crescimento de raízes.

4. As características de fitotoxicidade apresentam variações temporais significativas correlacionadas com o regime de chuvas, o que não é observado para as características de citogenotoxicidade.

5. A proliferação celular foi afetada negativamente pelas amostras de água do Córrego do Pântano levando à redução do índice mitótico. Água e o sedimento não promoveram aumento na frequência de anormalidades cromossômicas.

\section{Agradecimentos}

À CAPES, pela concessão de bolsa a Luiz Carlos de Almeida Rodrigues e à FAPEMIG, pelo apoio financeiro.

\section{Literatura Citada}

Alvim, L. B.; Kummrow, F.; Beijo, L. A.; Lima, C. A. A.; Barbosa, S. Avaliação da citogenotoxicidade de efluentes têxteis utilizando Allium cepa L. Revista Ambiente \& Água - An Interdisciplinary Journal of Applied Science, v.6, p.255-165, 2011.

Andrade, L. F.; Davide, L. C.; Gedraite, L. S. The effect of cyanide compounds, fluorides, aluminum, and inorganic oxides present in spent pot liner on germination and root tip cells of Lactuca sativa. Ecotoxicology and Environmental Safety, v.73, p.626-31, 2010.

Baumgarten, M. G. Z.; Niencheski, L. F. H.; Veeck, L. Nutrientes na coluna da água e na água intersticial de sedimentos de uma enseada rasa estuarina com aportes de origem antrópica (RS-Brasil). Atlântica, v.23, p.101-116, 2001.
Bazai, Z. A; Achakzai, K. K. Effect of wastewater from Quetta city on germination and seedling growth of lettuce (Lactuca sativa L.). Applied Science Journal, v.6, p.380-382, 2006.

Bisognin, D. A.; Velasquez, L.; Widders, I. Cucumber seedling dependence on cotyledonary leaves for early growth. Pesquisa Agropecuária Brasileira, v.40, p.531-539, 2005.

Bollmann, H. A.; Marques, D. M. L. M. Influência da densidade populacional nas relações entre matéria orgânica carbonácea, nitrogênio e fósforo em rios urbanos situados em áreas com baixa cobertura sanitária. Engenharia Sanitária Ambiental, v.11, p.343-352, 2006.

Brasil. Conselho Nacional do Meio Ambiente. Resolução n. 344 de 25 de Março de 2004.

Brasil. Conselho Nacional do Meio Ambiente. Resolução n. 357 17 de Março de 2005.

Cardoso, L. M. N.; Chasin, A. A. M. Ecotoxicologia do cádmio e seus compostos. Série Cadernos de Referência Ambiental v.6. 1.ed. Salvador: Centro de Recursos Ambientais. 121p. 2001.

Corrêa, A. X. R.; Rörig, L. R.; Verdinelli, M. A.; Cotelle, S.; Férard, J.; Radetski, C. M. Cadmium phytotoxicity: Quantitative sensitivity relationships between classical endpoints and antioxidative enzyme biomarkers. Science of the Total Environment v.357, p.120-127, 2006.

Czerniawska-Kusza, I.; Kusza, G. The potential of the phytotoxkit microbiotest for hazard evaluation of sediments in eutrophic freshwater ecosystems. Environmental Monitoring and Assessment, v.179, p.113-121, 2011.

Fernandes, T. C. C.; Mazzeo, D. E. C.; Marin-Morales, M. A. Mechanism of micronuclei formation in polyploidizated cells of Allium cepa exposed to trifluralin herbicide. Pesticide Biochemistry and Physiology, v.88, p.252-259, 2007.

Garcia, J. C.; Simionato, J. I.; Almeida, V. C.; Palácio, S. M.; Rossi, F. L.; Schneider, M. V.; Souza, N. E. Evolutive Followup of the photocatalytic degradation of real textile effluents in $\mathrm{TiO}_{2}$ and $\mathrm{TiO}_{2} / \mathrm{H}_{2} \mathrm{O}_{2}$ systems and their toxic effects on Lactuca sativa seedlings. Journal of the Brazilian Chemical Society, v.20, p.1589-1597, 2009.

Gomes, L. S.; Silva, F. A.; Barbosa, S.; Kummrow, F. Ecotoxicity of Sludges Generated by Textile Industries: A review. Journal of Brazilian Society of Ecotoxicology, v.7, p.89-96, 2012.

Jardim, G. M.; Armas, E. D.; Monteiro, R. T. R. Ecotoxicological assessment of water and sediment of the Corumbataí River, SP, Brazil. Brazilian Journal of Biology, v.68, p.51-59, 2008.

Kranner, I.; Colville, L. Metals and seeds: Biochemical and molecular implications and their significance for seed germination. Environmental and Experimental Botany, v.72, p.93-105, 2011.

Lefevre, I.; Marchal, G.; Correal, E.; Zanuzzi, A.; Lutts, S. Variation in response to heavy metals during vegetative growth in Dorycnium pentaphyllum Scop. Plant Growth Regulation, v.59, p.1-11, 2009.

Leme, D. M.; Marin-Morales, M. A. Allium cepa test in environmental monitoring: A review on its application. Mutation Research, v.682, p.71-81, 2009.

Li, W.; Khan, M. A.; Yamaguchi, S.; Kamiya, Y. Effects of heavy metals on seed germination and early seedling growth of Arabidopsis thaliana. Plant Growth Regulation, v.46, p.45-50, 2005. 
Maila, M. P.; Cloete, T. E. Germination of Lepidium sativum as a method to evaluate polycyclic aromatic hydrocarbons (PAHs) removal from contaminated soil. International Biodeterioration \& Biodegradation, v.50, p.107-113, 2002.

Mitteregger Júnior, H.; Ferraz-Dias, J.; Lúcia-Yonema, M.; Arenzon, A.; Silva, J.; Pegas- Henriques, J. A. Avaliação das atividades tóxicas e mutagênicas da água e do sedimento do Arroio Estância Velha, região coureira-calçadista, utilizando Allium cepa. Journal of Brazilian Society of Ecotoxicology, v.1, p.147-151, 2006.

Munzuroglu, O.; Geckil, H. Effects of metals on seed germination, root elongation, and coleoptile and hypocotyl growth in Triticum aestivum and Cucumis sativus. Archives of Environmental Contamination and Toxicology, v.43, p.203-213, 2002.

Rehman, A.; Bhatti, H. N.; Athar, H. Textile effluents affected seed germination and early growth of some winter vegetable crops: A case study. Water Air Soil Pollution, v.198, p.155163, 2009.

Ribeiro, L. O.; Barbosa, S.; Balieiro, F. P.; Beijo, L. A.; Santos, B. R.; Gouvea, C. M. C. P.; Paiva L. V. Fitotoxicidade de extratos foliares de barbatimão [Stryphnodendron adstringens (Mart.) Coville] em bioensaio com alface. Revista Brasileira de Biociências, v.10, p.220-225, 2012.
Singh, K. K.; Rastogi, R.; Hasan, S. H. Removal of cadmium from wastewater using agricultural waste 'rice polish'. Journal of Hazardous Materials, A121, p.51-58, 2005.

Tigini, V.; Giansanti, P.; Mangiavillano, A.; Pannocchia, A.; Varese, G. C. Evaluation of toxicity, genotoxicity and environmental risk of simulated textile and tannery wastewaters with a battery of biotests. Ecotoxicology and Environmental Safety, v.74, p.866-873, 2011.

Wierzbicka, M.; Obidzinska, J. The effect of lead on seed imbibition and germination in different plant species. Plant Science, v.137, p.155-171, 1998.

Wilke, B. M.; Riepert, F.; Koch, C.; Kühne, T. Ecotoxicological characterization of hazardous wastes. Ecotoxicology and Environmental Safety, v.70, p.283-293, 2008.

Wimmer, M. A.; Mühling, K. H.; Läuchli, A.; Brown, P. H.; Goldbach, H. E. The interaction between salinity and boron toxicity affects the subcellular distribution of ions and proteins in wheat leaves. Plant, Cell and Environment, v.26, p.1267-1274, 2003.

Žaltauskaite, J.; Čypaitè, A. Assessment of landfill leachate toxicity using higher plants Assessment of landfill leachate toxicity using higher plants. Environmental Research Engineering and Management, v.46, p.42-47, 2008. 